DOI 10.37882/2223-2982.2021.12.21

\title{
ФИЗИЧЕСКАЯ КУЛЬТУРА КАК СРЕДСТВО РАЗВИТИЯ СТУДЕНТОВ С ОСОБЫМИ ОБРАЗОВАТЕЛЬНЫМИ ПОТРЕБНОСТЯМИ
}

\section{PHYSICAL CULTURE AS A MEANS OF DEVELOPING STUDENTS WITH SPECIAL EDUCATIONAL NEEDS \\ K. Okatenko \\ A. Morozov}

Summary: This scientific research defines the basics of the psychological and pedagogical structure of the high education for students as teachers at future for the connection of inclusive and common preparing in the process of education in physical learning. The author speaks about the components of inclusion both in general context and in the specifics of education in physical culture, defining the key points of professional education. By context, the analysis of the main problematic issues arising during the implementation of inclusive education, innovative methods of working with real educational situations is carried out. The article also examines the components and levels of practice for students at schools, special sport trainings to integrate inclusive elements in the module of physical training as an integral factor of learning success.

Keywords: inclusive education, physical education, teacher competence, training model, readiness components, teacher readiness levels, content of pedagogical education.
Окатенко Ксения Валерьевна преподаватель, Павлодарский Педагогический Университет, Казахстан, г. Павлодар

Kseniya22.08.1994@maii.ru

Морозов Артем Александрович Старший преподаватель, Павлодарский Педагогический Университет, Казахстан, г. Павлодар

Swim84@mail.ru

Аннотация: В статье определены основы психолого-педагогического содержания подготовки будущих учителей к реализации инклюзивного образования в процессе физического воспитания. Автор рассматривает содержание инклюзии как в общем плане, так и в специфике физического воспитания, определяя ключевые моменты профессиональной подготовки будущих педагогов. Кроме того, проводится анализ основных проблемных моментов, возникающих в ходе реализации инклюзивного образования, инновационные методы работы с реальными образовательными ситуациями. В статье также рассматриваются компоненты и уровни готовности будущих педагогов к реализации инклюзивного образования в процессе физической подготовки как неотъемлемого фактора успешности обучения.

Ключевые слова: инклюзивное образование, физическое воспитание, компетентность учителя, модель подготовки, компоненты готовности, уровни готовности педагога, содержание педагогического образования.
A ктуальность статьи обусловлена тем, что на различных этапах образовательного процесса в его содержание максимально включается понятие «инклюзия». Инклюзивное образование и воспитаниеодин из неотъемлемых элементов системы образования в большинстве зарубежный стран еще со второй половины прошлого столетия. На настоящий момент данная тенденция актуальна и для России, так как современная законодательная база, регулирующая деятельность в сфере образования («Закон об образовании» РФ) позволяет включать обучающихся с разным анамнезом и комплексностью заболеваний в систему дошкольного, основного общего, дополнительного и вузовского образования. Именно поэтому в системе образования возникает противоречие между увеличением численности специфической категории учеников и недостаточной подготовленностью учителей к работе с ними. В образовательном процессе среднего специального и высшего образования не всегда учитывается запрос «особенных» получателей образовательных услуг, и зачастую, будущие учителя получают лишь предметные знания. При этом уровень сформированности межпредметных компетенций у них недостаточен для профессиональной деятельности. При построении процесса подготовки к физическому воспитанию преподавателю важно сопровождать процесс трансформации предметных и межпредметных компетенций в учебной деятельности в профессиональные базисные компоненты. В основном, это достигается путем увеличения практической подготовки и включения узкоспециальных дисциплин в учебный план.

Кроме того, социальный запрос на преподавателей в области физического воспитания обусловлен, с одной стороны, актуальностью поддержания, сохранения и улучшения уровня здоровья обучающихся, а с другойнеобходимостью вовлечения в процесс физического воспитания лиц с инвалидностью и ОВ3 и соответственно, высоким уровнем компетентности учителей в данной сфере. Это обусловлено тем, что содержание инклюзивного образования, особенно, в сфере физического воспитания, отражает доступность обучения и воспитания для всех категорий обучающихся, ориентируясь на содержание Закона об образовании и Национального 
проекта «Доступная среда». Это включает в себя адаптацию условий обучения, пространства, специальных приспособлений (пандусов, лифтов, тактильных дорожек) для обучающихся с особыми образовательными потребностями. Большинство образовательных учреждений в регионах Российской Федерации участвуют в проектах, связанных с интеграцией лиц с инвалидностью и ОВ3 в социальную действительность. При этом важно учитывать, что физическая культура- это обязательный для изучения предмет на всех ступенях образования, а физическое воспитание- один из элементов современной системы воспитания. Кроме того, современное общее и инклюзивное образование ориентировано на индивидуальный подход, дифференцированное обучение, поэтому каждый учитель, помимо предметной, должен обладать еще и психологической компетентностью.

Целью данного исследования является определение основ психолого- педагогического содержания подготовки будущих учителей к реализации инклюзивного образования в процессе физического воспитания

Для достижения данной цели нами определен ряд задач:

1. Выявить специфику подготовки будущих учителей к реализации инклюзивного образования;

2. Исследовать структуру (компоненты и уровни) готовности учителей к работе с обучающимися с OB3;

3. Определить психолого- педагогические основы подготовки будущих учителей в процессе физического воспитания.

Методы исследования:

1. Теоретические: теоретико- методологический анализ современной литературы в области педагогики высшей школы, инклюзивного образования, физического воспитания;

2. Эмпирические: исследование опыта образовательных учреждений в сфере реализации инклюзии в процессе физического воспитания обучающихся;

3. Практические: беседа, опрос студентов педагогических специальностей, в том числе, будущих учителей физической культуры на базе вузов г. Волгограда.

Развитие системы образования в Российской Федерации отражает социальную ситуацию в стране в целом, а также предъявляет новые требования к личностным и профессиональным качествам учителя, в том числе, реализующего инклюзию в процессе физического воспитания. Это безусловно актуализирует изучение специфики подготовки будущих учителей в сфере физического воспитания. На современном этапе Российской действительности актуализируется тенденция оценки качественных показателей, которые представляют цен- ность для оценки уровня развития профессиональных и личностных качеств, а также мониторинга достижений выпускников. [1] Содержание образовательного процесса в данном случае обусловлено, с одной стороны особенностью физического воспитания, как направления профессиональной деятельности, с другой- наличием «особой» аудитории обучающихся- имеющих специфические образовательные потребности.

Для определения специфики подготовки будущих учителей нам необходимо определить компоненты профессиональной компетентности, которые обуславливают содержание образовательного процесса. В структуре узкоспецифических компетенций и общей компетентности учителя, работающего в инклюзивной образовательной среде, можно выделить мотивационный, познавательный, деятельностный и рефлексивный компоненты [3]. Именно совокупность данных компонентов позволяет максимально эффективно реализовывать процесс инклюзии в физическом воспитании, так как тесно взаимосвязаны и оказывают существенное влияние на формирование образовательного пространства и структуру подготовки. При этом также возможно говорить о поэтапности развития данных компонентов, когда вначале у студентов развивается и закрепляется мотивация к работе с данной категорией обучающихся именно в сфере физического воспитания, затем они осознают, что необходимо и получают нужные знания и только после этого будущий учитель «пропускает через себя» проблематику работы в инклюзивной сфере образования. Организационно- деятельностный компонент в данном случае, является показателем усвоения студентами профессиональных навыков, «фишек» работы, особенностей организации воспитательного процесса с инвалидами и отражения их в процессе физического воспитания. Однако, включение в деятельность элементов инклюзивного образования возможно лишь при активизации рефлексивного компонента, который обусловлен уровнем мотивации учебной, профессиональной деятельности (Е.В. Гавришова, А.А. Третьяков), а также мотивации достижения - организации физического воспитания с лицами с ОВЗ. А.Г. Асмолов, В.К. Бальсевич, в работе по физическому воспитанию основной является мотивационная составляющая [4]. Подготовка будущих учителей в плане психолого- педагогического сопровождения физического воспитания отражает формирование гуманистических ценностей, сочетание профессиональных и личностных мотивов в специально созданной инклюзивной образовательной среде. Практическая направленность физического воспитания придает процессу подготовки инструментальный характер. И в данном случае необходимо обращать внимание на прикладной аспект физического воспитания- разработку специальных занятий и упражнений для реализации инклюзивного образования, подготовку специального учебного пространства. Когда физическое воспитание в образовательном учреждении реализуется с учетом ин- 
новационных технологий, вовлекая современные тренажеры, музыкальное сопровождение, Smart- технологии, тогда учитываются общие и специфические потребности учеников, формируется их учебная мотивация, а соответственно ценностно- смысловая ориентация воспитания приобретает социально значимый характер. Структурные и содержательные аспекты нацеливают обучающихся не только на воспитательный процесс, но и на достижение результатов, создание ситуаций успеха, повышения самооценки и уверенности в себе.

Исходя из анализа исследований отечественных авторов (Будникова Е.С., Чаулина М.С.) структура готовности будущего учителя отражает нижеуказанные составляющие: когнитивная, рефлексивная и деятельностная. Они находят непосредственное отражение в модулях подготовки, на которых необходимо остановиться немного подробнее. Одно из направлений -продуктивное. Оно включает в себя результативность профессиональной деятельности (Грачев А.С.), ориентацию на достижение результата обучающимися и подхода к физическому воспитанию как достижению учащимися личностно и социально значимых результатов.

Деятельностная компонента подготовки закрепляет мотивацию деятельности, моральное удовлетворение от профессиональной деятельности, способствует структурированию процесса воспитания и определению его структурных элементов.

Рефлексивный компонент методологической структуры профессионального образования является необходимым элементом трансформации деятельности студентов, смоделированной в процессе обучения в профессиональную, общественно значимую деятельность учителя, когда процесс физического воспитания рассматривается не только как общая физическая подготовка учащихся, элемент занятий спортом, но и как компонент многогранного понятия «воспитание», отражающего и развивающий и обучающий аспекты. При этом целевые ориентиры обучения и физического воспитания смещаются с результативных и процессуальных на личностные, отражающие психолого- педагогические и нозоологические особенности обучающихся.

В ходе работы нами было проведено практическое исследование среди студентов Волгоградского социально- педагогического университета на предмет сформированности профессиональных компетенций в области инклюзивного образования, в том числе, и физической подготовки. В исследовании принимали участие 25 студентов педагогических специальностей. Со студентами проводились опросы на курсе, а также в малых группах и индивидуально на предмет выявления специфики подготовки будущих учителей к работе в инклюзивной образовательной среде.
В качестве основных результатов была отмечена сформированность предметных навыков у студентов по специальности (75\%), при этом готовность работы в сфере инклюзии у будущих педагогов находится на среднем уровне (45\%), что сами студенты объяснили недостаточной теоретической подготовкой по работе с людьми с ОВ3 и сложностью в прохождении практики в образовательных учреждениях, где есть обучающиеся с ОВ3.

15\% будущих учителей не осознают специфики работы с обучающимися с ограниченными возможностями и в профессиональной деятельности намерены реализовывать общие методы и направления физического воспитания.

Важно подчеркнуть, что исследование проводилось среди бакалавров выпускных курсов и при этом лишь $1 \%$ на практике видели или с помощью педагогов- наставников апробировали профессиональную деятельность с элементами инклюзивного образования.

Данное исследование максимально подчеркивает актуальность определения психолого- педагогических особенностей подготовки будущих учителей и позволяет выявить основные ее направления. В беседе большинство студентов подчеркнули, что в процессе обучения необходимо разрешение практических ситуаций, связанных с элементами инклюзии, в том числе, и в физическом воспитании обучающихся. Это обусловлено тем, что профессиональная деятельность учителя связана не только с преподаванием определенного предмета, но также с охраной жизни, здоровья обучающихся, закреплением полезных привычек и формированием здорового образа жизни, в том числе, у обучающихся с OB3. Социальная установка будущего учителя ориентирована на достижение целей, гораздо более масштабных, чем реализация физического воспитания в рамках конкретной образовательной организации или учреждения. Она заключается в формировании мировоззрения, отражающего общечеловеческие, гуманистические ценности, которые при этом приобретают практический характер, реализуясь в образовательном процессе. Одним из направлений формирования и закрепления мотивации к активному физическому воспитанию является предоставление обучающимся альтернативных способов проведения занятий в соответствии с их возможностями, образовательными целями, мотивами, а говоря о лицах с ОВ3, с учетом диагноза, группы здоровья и желания участвовать в различных видах активностей. 27\% респондентов отметили необходимость включения в процесс физического воспитания соревновательных элементов, 51\%-подчеркнули важность взаимодействия учителя и ученика при проведении занятий и тренировок и ориентацию на потребности обучающихся с ОВ3 и инвалидностью. При составлении плана для педагогических специальностей, очень важно ориентироваться на специфику работы с различными категориями 
обучающихся и предметную область (физическое воспитание), необходимо обучать студентов технологиям, методам физического воспитания, которые позволяют дифференцировать образовательный процесс для обучающихся из групп здоровья 1, 2, специальной группы. Студентам необходимо научиться учитывать специфику диагноза- соматика, интеллектуальные нарушения, комплексность заболеваний, для того чтобы обеспечить их максимальное участие в физическом воспитании. Существуют виды физической активности, которые подходят всем видам обучающихся- это ходьба, командные виды, несложные физические упражнения без применения снарядов и тренажеров.

Отражая масштаб включения в образовательный процесс в среднеспециальных и высших учебных заведениях элементов инклюзии, а также появление в детских садах, школах и учреждениях дополнительного образования обучающихся с ОВ3, для будущих учителей на уровне бакалавриата и магистратуры необходима разработка специальных курсов, модулей, блоков в подготовке, в том числе, и в сфере физического воспитания, ориентированных на овладение навыками работы с категорией обучающихся с особыми образовательными потребностями [3] - это узкоспециальные дисциплины по выбору, элективные курсы, которые включены в учебный план и отражают не только предметные, но и межпредметные компетенции. При этом равноценно важно получение психологических и педагогических знаний, так как работа педагога в сфере инклюзии отражает знание личностных, коммуникативных особенностей, обучающихся с ОВЗ и инвалидностью, влияния диагноза на мотивацию физического воспитания и уровень достижения максимальных результатов. Учителю необходимо знать нозоологический статус обучающегося для того, чтобы дифференцировать физическое воспитание нормотипичных обучающихся и лиц с ОВ3, разработать специальные методики воспитания и включаться в индивидуальные программы развития (ИПР и СИПР). Очень важна в данном контексте, взаимосвязь студентов с педагогами-практиками, которые могут быть наставниками на начальном этапе профессиональной деятельности. И именно в процессе взаимодействия с наставниками возможно говорить о трансформации личностной мотивации (стремление помочь детям, которые не имеют таких возможностей как их сверстники, научить их чему- либо) в профессиональную, социально значимую (обучение, физическое воспитание, интерес к педагогической деятельности). Кроме того, студенты учатся работать в команде, т.к. физическое воспитание В инклюзивной сфере предполагает взаимодействие с различными специалистами: психологом, социальным педагогом, реабилитологами. Будущие учителя учатся работать с индивидуальными планами и программами развития обучающихся, формируют проективные навыки профессиональной деятельности.

В ходе исследования посредством реализации задач мы определили специфику подготовки будущих учителей к реализации инклюзивного образования, отражающая сочетание различных компонентов профессиональной компетентности будущего учителя и влияние на профессиональную деятельность специфики категории обучающихся с ОВЗ. Говоря о современном образовательном процессе в высшей школе, нельзя снижать значение психолого- педагогического сопровождения самих студентов, как субъектов профессиональной подготовки. Объём информации, категории обучающихся, с которыми в дальнейшем придется работать будущим учителям, а также специфика физического воспитания, обуславливает необходимость создания службы психологической помощи, активизации работы преподавателей вуза в качестве кураторов курсов, которые могут вовремя помочь найти решение проблемы, способствуют процессу адаптации к профессиональной деятельности.

Подводя итоги нашего исследования, необходимо отметить главную особенность подготовки студентов для реализации процесса физического воспитания в инклюзивном образовании, а именно- практическую направленность профессиональной деятельности, которая носит динамический характер, учитывая тенденции развития современного общества, и, попутно отражает в обучающихся специфику реализации инклюзивного образования. Одним из ключевых факторов успешной реализации инклюзивных технологий физического воспитания при этом можно назвать сочетание внутренних условий подготовки и внешних показателей готовности будущих учителей к включению элементов инклюзии в процесс физического воспитания.

При этом необходимо говорить не только о сочетании теоретических и практических элементов в подготовке будущих педагогов, но и об интегративном характере образовательного процесса, который позволяет решать задачи обучающего, развивающего и воспитательного плана в реализации элементов инклюзивности в физической подготовке.

\section{ЛИТЕРАТУРА}

1. Андрианова Е.И. Критерии и показатели готовности будущих педагогов физической культуры к работе в инклюзивной образовательной среде детей с ограниченными возможностями здоровья // Вестник НовГУ. 2017. №1 (99). URL: https://cyberleninka.ru/article/n/kriterii-i-pokazateli-gotovnostibuduschih-pedagogov-fizicheskoy-kultury-k-rabote-v-inklyuzivnoy-obrazovatelnoy-srede-detey-s (дата: 25.11.2021). 
2. Будникова Е.С., Резникова Е.В. Реализация инклюзивного образования в образовательной организации [Текст]: учебное пособие для студентов высш. учеб. заведений / Е.С. Будникова, Е.В. Резникова. - Челябинск: Изд-во Цицеро, 2017. - 110с.

3. Бурханова И.Ю., Скитневский В.Л., Чаулина М.С. Подготовка педагога по физической культуре к осуществлению профессиональной деятельности в условиях инклюзивного образования // Известия ТулГУ. Физическая культура. Спорт. 2018. №2. URL: https://cyberleninka.ru/article/n/podgotovka-pedagogapo-fizicheskoy-kulture-k-osuschestvleniyu-professionalnoy-deyatelnosti-v-usloviyah-inklyuzivnogo-obrazovaniya (дата обращения: 25.11.2021).

4. Гавришова Е.В., Волошина Л.Н., Третьяков А.А., Грачев А.С. Изучение особенностей мотивации студентов к занятиям физической культурой // Известия ТулГУ. Физическая культура. Спорт. 2018. №2. URL: https://cyberleninka.ru/article/n/izuchenie-osobennostey-motivatsii-studentov-k-zanyatiyam-fizicheskoykulturoy (дата обращения: 25.11.2021).

(с) Окатенко Ксения Валерьевна (Kseniya22.08.1994@maii.ru), Морозов Артем Александрович (Swim84@mail.ru).

Журнал «Современная наука: актуальные проблемы теории и практики»

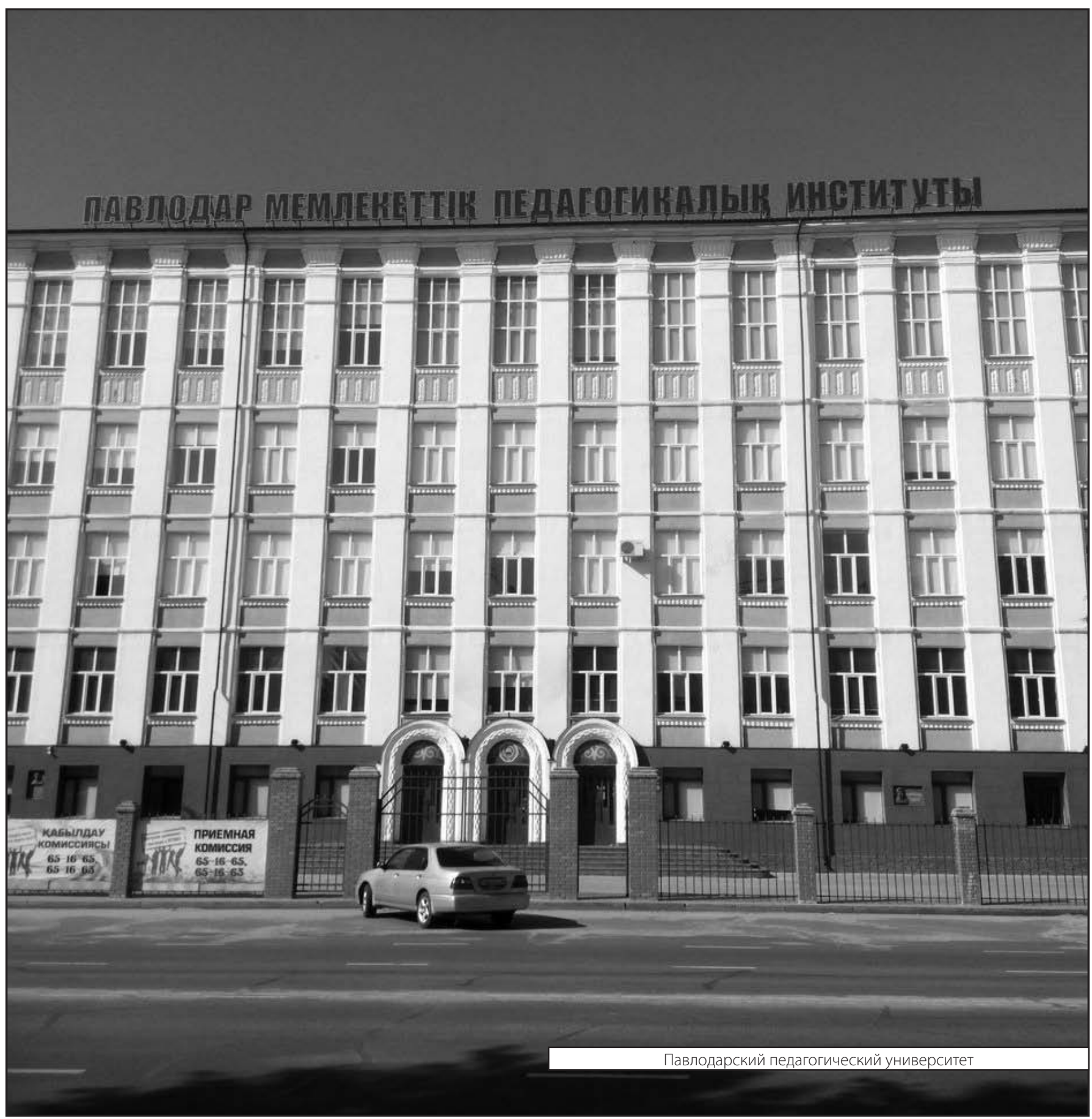

